\title{
Simulation of dynamic properties of a spindle and tool system coupled with a machine tool frame
}

\author{
Petr Kolar • Matej Sulitka • Miroslav Janota
}

Received: 10 February 2010 / Accepted: 25 August 2010/Published online: 7 September 2010

(C) Springer-Verlag London Limited 2010

\begin{abstract}
The cutting performance relates to the dynamic properties of the whole system of the tool, spindle, and machine tool frame. The impact of the machine frame properties on the dynamic properties at the tool end point is studied both experimentally and using a coupled simulation model. Coupled model of the whole mechanical system is created as a system joining the spindle detailed model and machine frame FE model. Shift in the spindle and tool system dynamic properties, related to the machine frame properties, is proved using the coupled model. Experimental verification of the FRF evaluated at the tool is extended also by cutting tests. Good match of the simulated dynamic properties of the whole system with the real behavior is found.
\end{abstract}

Keywords Spindle dynamic properties · Machining productivity Machine frame and spindle coupled model . Modal decomposition · FEM

\section{Nomenclature}

$A, B, C, D$ state space matrices

$\boldsymbol{E} \quad$ identity matrix

$\Lambda \quad$ spectral matrix

$q \quad$ vector of displacements in modal coordinates

$y \quad$ vector of displacements in physical coordinates

P. Kolar $(\bowtie) \cdot$ M. Sulitka $\cdot$ M. Janota

Research Center of Manufacturing Technology,

Czech Technical University in Prague,

Prague, Czech Republic

e-mail: p.kolar@rcmt.cvut.cz

URL: http://www.rcmt.cvut.cz

\section{Introduction}

High-performance cutting (HPC) is a workpiece roughing technology that makes it possible to reach high volumes of removed material. The success of HPC operations depends on the limits of interaction between the cutting process and the machine tool. This can be limited by installed power of the machine tool spindle or by the occurrence of chatter vibration.

Chatter is characterized by heavy vibration, tool damage and poor surface quality. Research on chatter vibrations has a very long history. The first author to mention the chatter issue was Taylor [35]. Later research during the 1940s focused on the negative damping effect [4, 12]. During the 1950s and 1960s, Tlusty et al. [36, 37], Koenigsberger and Tlusty [13], Tobias [40-42], and Merrit [21] recognized that chatter is associated with the structural dynamics of the machine tool and the feedback between subsequent cuts due to regeneration of the waviness effect. Tlusty and Tobias also described the mode coupling effect as a second chatter mechanism. Shridhar et al. [34] proposed detailed mathematical models of the milling system. Hanna and Tobias [7], Shi and Tobias [33], and Tlusty and Ismail [38, 39] studied nonlinear chatter and modified the previous linear theory. Smith et al. [30] described influence of the tool length to chatter stability. Altintas and Budak $[2,5]$ used multi-frequency solution of the chatter prediction. A summary of the cutting stability research is presented in [3].

All methods for predicting cutting stability need information about the dynamic properties of the whole machine tool system. This is usually expressed by the frequency response function (FRF) at the tool center point or at the workpiece. The FRF is unique for every machine-holdertool combination. The FRF can be measured or computed.

The FRF can either be significantly influenced by only one part of the system (e.g., a long slim tool or a long ram) 
or it can be a balanced result of interaction between the machine tool structure, the spindle, and the tool. Moreover, chatter can be influenced by the feed drive control in specific cases [32]. The easiest way to evaluate the FRF is to use a modal hammer for excitation of the mechanical system and to measure the system response with an accelerometer. However, if a high number of tools with different lengths, diameters, and holder types should be investigated, measurements can become too much timeconsuming. Significant simplification in such a case can bring combination of measured and simulated characteristics. Dynamic properties of the machine tool frame with spindle can be advantageously measured, whereas the tool properties can be computed using the FE models. Consequently, for the evaluation of the whole system properties, e.g., receptance coupling substructure analysis method can be employed. The method was presented by Schmitz [26-28]. Park [24] proposed method of identifying the end mill-spindle/tool holder joint dynamics, which include both translational and rotational degrees of freedom.

Commonly, measurements of the system dynamic properties are performed with non-rotating tool and spindle. However, with respect to the cutting process characteristics, the spindle properties under rotation are decisive, since the gyroscopic and centrifugal effects acting on the rotating parts shift the spindle dynamic properties. Rantatalo [25] presented contactless dynamic spindle testing equipment used to study the effect of the gyroscopic moment and the speeddependent bearing stiffness on the system dynamics. Kreis [15] used an active magnetic bearing to identify the dynamical properties of the spindle and tool during rotation.

The main advantage of the measurement methods is that at a particular point of the time the whole structure, i.e., tool, tool holder, spindle design, and machine structure is taken into account. However, if a new machine tool is designed or the dynamic properties of an already existing machine tool and spindle are to be analyzed and optimized, model of the mechanical system has to be created.

For simulating the spindle dynamic properties, various models with different level of their complexity have been developed. In 1976, Nelson and McVaugh [22] published a FEM formulation of a rotor bearing system based on the Euler-Bernoulli beam theory including also the effect of the gyroscopic moments and the centrifugal forces. In 1980, Nelson [23] presented another formulation based on the Timoshenko beam theory including the shear deformation effects. In 1960, Jones [11] presented a general theory for elastically constrained ball and radial roller bearings under arbitrary load and speed conditions. Harris [8] published a model of a ball and cylindrical bearing under rotation with respect to external load, internal bearing kinematics, and internal friction and gyroscopic moments. Li and Shin [17, 18] and Lin et al. [19] developed a thermo-mechanical bearing model. Holkup [10] described a finite-elementmethod-based thermo-mechanical model of a spindle with rolling bearings.

Dynamic properties evaluated at the spindle nose or the tool refer not only to the single spindle, but also to the properties of the attached machine tool structure. Cao and Altintas [6] presented a general method for modeling a spindle-machine tool system that consists of the cutter, tool holder, spindle shaft, bearings, housing, and the machine tool. In this case, the machine was represented by a simple beam substitute model which was developed by means of experimental modal analysis. Albertelli et al. [1] showed two variants of modeling of the machine tool frame and spindle coupled system. The first one employs a simplified model of the machine tool frame represented also by beam elements and additional masses; the second one is based on creating the full FE model of a machine frame and spindle modeled using the beam elements.

However, the simplified representation of the machine tool or spindle dynamic properties within the machine frame and spindle coupled model is not sufficient enough for relevant capturing of the dynamic properties of the whole system. On the other hand, full FE models can provide closer match of the simulated and measured properties. Though, the drawback of the full FE model is that the spindle can be represented by beam elements enabling the simulation of only the spindle static properties.

The paper presents an approach of creating the spindle and machine frame coupled model, which provides the possibility of joining the spindle detailed dynamic model with the machine tool FE model. The spindle model uses reduced FE description of geometrical parts and the Harris' bearing model [8], enabling to simulate also the spindle dynamic properties under rotation. Importance of the spindle and machine frame coupled modeling for relevant prediction of the real system dynamic properties is illustrated by an example of a column type machine tool. An experimental analysis of the machine frame impact on the dynamic properties evaluated at the spindle nose or a tool is performed. The influence of the machine tool frame is discussed also with respect to various kinds of tools with different compliance. The coupled model has been validated by performing the frequency response and cutting tests.

\section{Influence of the machine tool frame on the dynamic properties of the spindle and the tool system}

\subsection{Spindle without the tool}

Impact of the machine tool frame on the spindle dynamic properties is studied using an example of a three-axis horizontal milling machine. The machine structure repre- 
sents a very common type of the machine tool design with moving column (Fig. 1). The machine tool is equipped with a motorized spindle with a maximum speed of $12,000 \mathrm{rpm}$ and maximum power of $25 \mathrm{~kW}$, built in the machine ram (Fig. 2). For capturing the influence of the machine tool frame, dynamic properties at the spindle nose are evaluated both for the case of a spindle free-free state (Fig. 3) and spindle mounted in the machine tool.

Figure 4 shows a comparison of FRFs measured on a free-free spindle (solid line) and a spindle mounted in a machine (dashed line). On its own, the spindle features one dominant compliance close to the frequency of $870 \mathrm{~Hz}$. However, if the spindle is connected to the machine tool frame, the biggest compliance occurs in the frequency range of up to $150 \mathrm{~Hz}$. Dynamic compliance in this frequency range is attributed to the machine frame eigenfrequencies. It may also be seen that the eigenfrequency close to $870 \mathrm{~Hz}$, which is related to the free-free spindle, slightly shifts to the value of $903 \mathrm{~Hz}$ if the spindle is mounted in the machine frame.

\subsection{Spindle with a tool}

The FRF measurements were also carried out on two different tools: a face milling cutter with the diameter of $50 \mathrm{~mm}$ and total length of $60 \mathrm{~mm}$ (referred to as H50) and a modular shank cutter with the diameter of $32 \mathrm{~mm}$ and total length of $175 \mathrm{~mm}$ (referred to as S32M; see Fig. 5). The first tool is an example of a very compact and stiff tool for high-performance cutting. The other one represents an example of a slim compliant tool.

If the H50 face milling cutter is considered, the findings of the machine frame impact on the dynamic properties at the tool tip are similar to the case of the spindle without the tool, as discussed in the chapter 2.1. The spindle with the

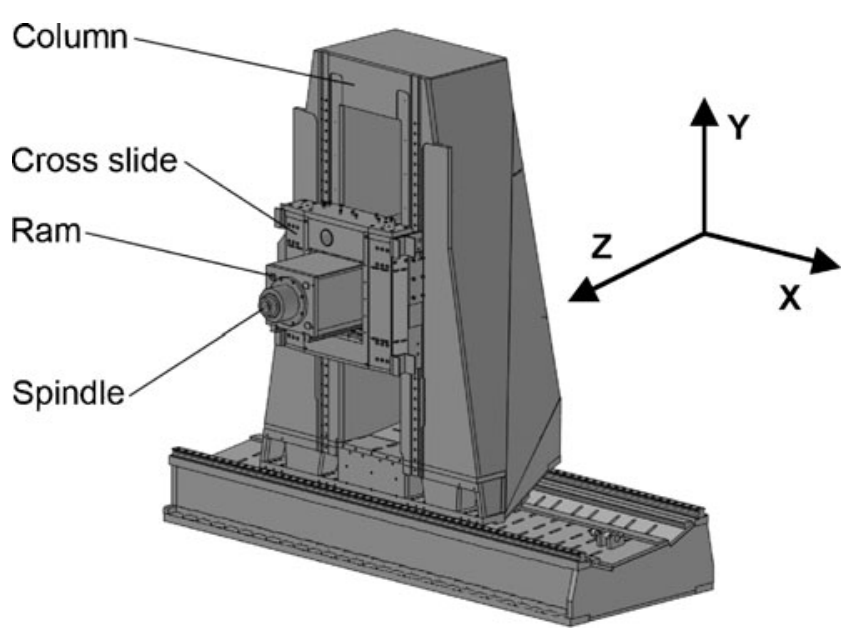

Fig. 1 Milling machine used for verification

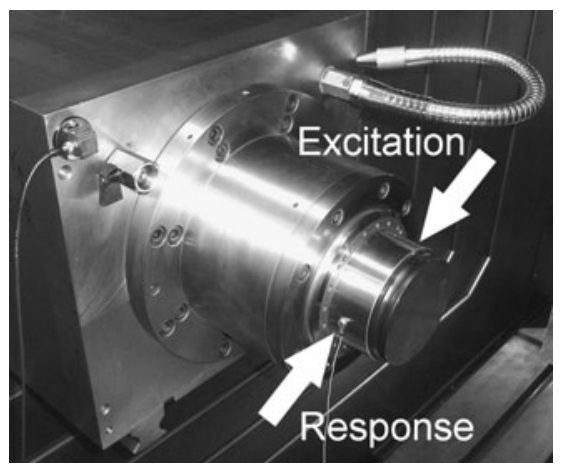

Fig. 2 Measurement of FRF on a spindle built in the ram

$\mathrm{H} 50$ tool is characterized by one significant compliance close to the frequency of $817 \mathrm{~Hz}$. Other less dominant frequencies occur in the range between 1,000 and $2,000 \mathrm{~Hz}$ (Fig. 6). If the spindle is connected to the machine frame, the dominant frequency of the tool-spindle system increases to $871 \mathrm{~Hz}$. Damping also increases at this frequency. However, critical compliances arise in the low frequency range.

Figure 7 shows the FRFs of a spindle with the S32M modular shank cutter. The tool mounted in the free spindle features one dominant eigenfrequency of $1,048 \mathrm{~Hz}$. This frequency remains dominant when the spindle with the tool is mounted in the machine frame. However, in this case, compliance at this critical frequency is significantly reduced due to the enhanced damping of the spindle joined with the machine frame. Except for the enhanced damping at the critical frequency, the machine frame does not show any other influence on the value of the critical compliance.

As the above shown examples prove that the critical compliance of the tool-spindle-machine system depends on the dynamic properties of each part in this chain. For relevant prediction of the tool dynamic properties, it is therefore important to create the coupled models of the machine tool-spindle-tool system, by using which the parts with critical compliance in the whole system can effectively be detected.

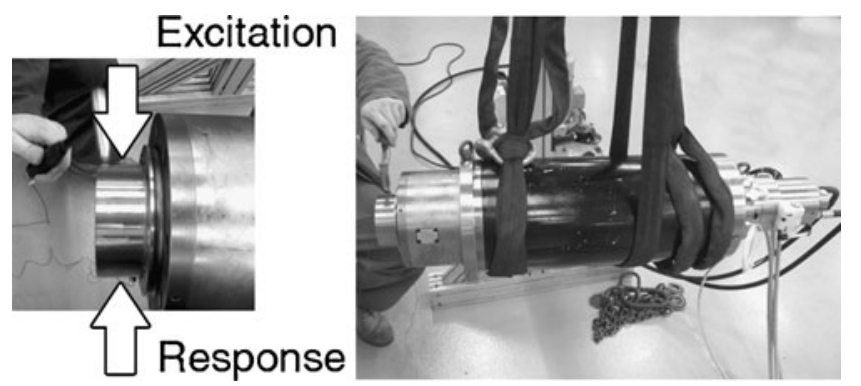

Fig. 3 Measurement of FRF on a free-free spindle 


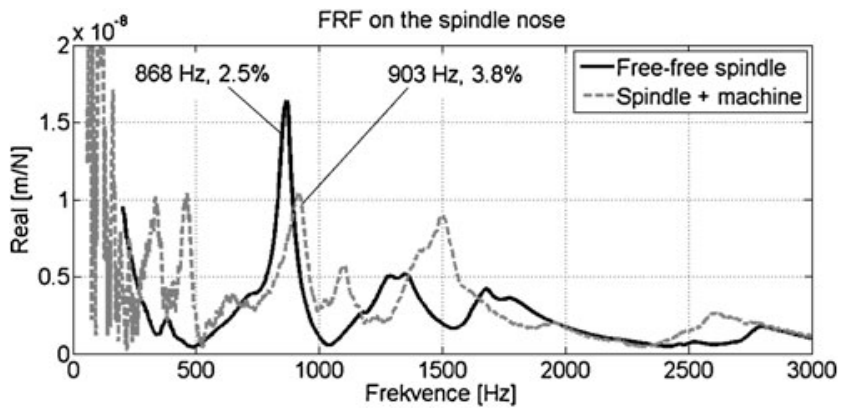

Fig. 4 Measured FRF on the spindle nose

\section{Description of the coupled model}

3.1 Strategy used to create the coupled model of the spindle and machine frame system

To create the coupled model, the strategy of joining separate models of the spindle and the machine tool frame is chosen. The mathematical method used for coupling the models is based on transforming the spindle and machine frame FE models into the state space with reduction in modal coordinates and coupling the bodies in the state space by introducing the force interaction between the selected interference points. This strategy of coupling the models of flexible bodies corresponds with the approaches of flexible multi-body modeling employed in the machine tool field (e.g., [9, 16, 20, 29, 44]).

The spindle is connected with the machine ram in two points representing the real fixing of the spindle on its front and back flange. A corresponding pair of interface points is created on the machine frame model as well. Force interaction in the interface points is realized by means of spring elements with the defined stiffness in $X, Y$, and $Z$ directions. Connection on the front flange is considered as rigid, which is represented in the model by a spring stiffness value of $10^{12} \mathrm{~N} / \mathrm{m}$ in the $X, Y$, and $Z$ directions. On the back flange, spindle is supported in the ram only in the radial directions $(X$ and $Y$ ), in which the springs with the stiffness values of $10^{12} \mathrm{~N} / \mathrm{m}$ are used.
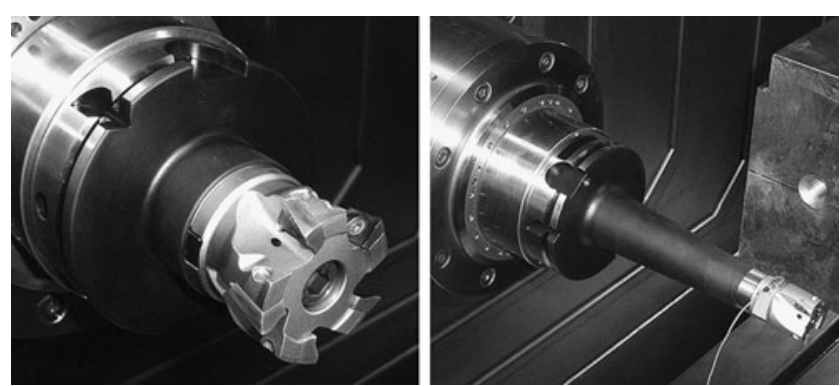

Fig. 5 Tools considered: face milling cutter H50 (left) modular shank cutter S32M (right)

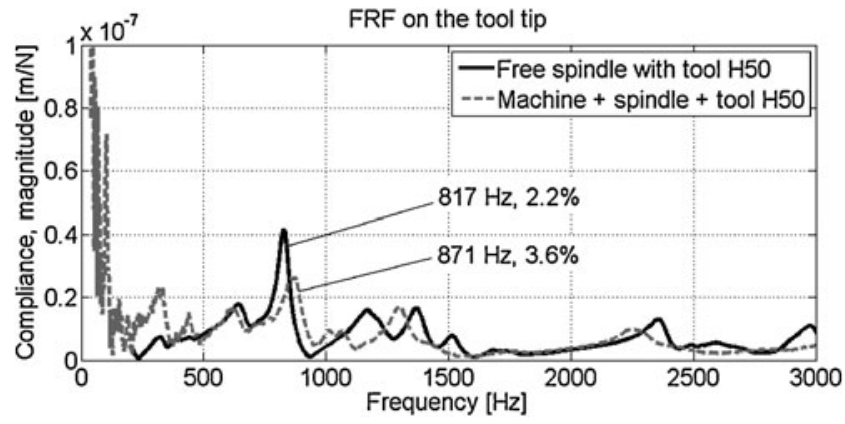

Fig. 6 FRF on the H50 face milling cutter tool tip

The machine frame model uses a simplified representation of the $X, Y$, and $Z$ ball screw feed drive structures using a linear spring elements with a high stiffness value of $10^{12} \mathrm{~N} / \mathrm{m}$, which is used to represent the static stiffness of the feed drive position controller. Since the machine tool is equipped in all of the motion axes by a position direct measurement, the above-mentioned approach is used to represent the static stiffness of the feed drive position control. Strategy of creating more detailed feed drive coupled models is described, e.g., in [43].

\subsection{Spindle model}

The spindle model consists of a description of the spindle and tool geometry, an analytical model of bearings, and information about system damping [14].

The geometry of the spindle shaft, the spindle housing, and the tooling system is described by mass and stiffness matrices. A volumetric model of the spindle geometry and its corresponding FE mesh has been created in the ANSYS software using the APDL programming language. Guyan's reduction method for reduction of the number of DOFs has been applied on the FE mesh for selected nodes. The result is a one-dimensional model with elements having six DOFs in each node instead of the initial volumetric mesh with three DOFs in each node. The properties of other spindle components (bearings, tool holder-spindle interface) are described by corresponding stiffness matrices.

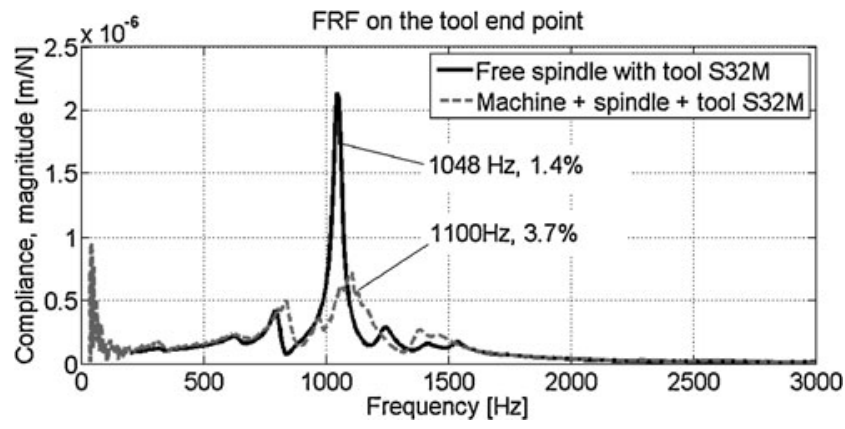

Fig. 7 FRF on the S32M shank cutter tool tip 
The calculation of the bearing stiffness matrix is based on the model described by Harris [34]. There are three kinds of equations that define the bearing:

- Hertzian force-deflection characteristics of ball-ring contacts in the normal direction

- Force and moment equilibrium on bearing balls

- Geometric formulas stating the relation of bearing ring positions, contact angles, and ball-ring normal deflection

The bearing model uses the Newton-Raphson method to solve the "internal condition" of bearings (contact forces, angles, rigidity) resulting from the "external condition" ring positions. The result for the bearing model is a complete stiffness matrix of each bearing in the assembly, including diagonal and off-diagonal elements. The model is also able to take into account the thermal conditions of the spindle [10].

First, the eigenvalue problem of an undamped system is solved. In the next step, the spindle model is transformed via the modal decomposition technique into a state-space description in which the modal damping of the system is introduced.

\subsection{Machine tool frame model}

The computational model of the machine tool structure is based on a simplified geometrical model that reflects all of the important structural parts of the machine. The geometrical model of the machine tool structure, as well as the computational FE mesh, have been prepared in the I-DEAS FEM software. A view of the FE model of the machine, with detailed depiction of one of the interface points for connection with the spindle model, can be seen in Fig. 8. The interface point is connected with a ring of slave nodes by means of rigid constraints (blue lines).

The design of the machine frame features an optimized ribbed structure with relatively thin walls, which allows for a representation of the machine structure by means of a shell FE mesh. A quadratic variant of the shell elements has been used.

\subsection{Creating a coupled model of the spindle} and the machine frame

The coupled model of the spindle and machine frame system has been assembled outside the FE environment using separate models which are reduced in modal coordinates by means of the modal decomposition technique. The reduced models are consequently transformed into a state-space description which maintains the appropriate force inputs and position outputs for establishing the force interactions in physical coordinates.

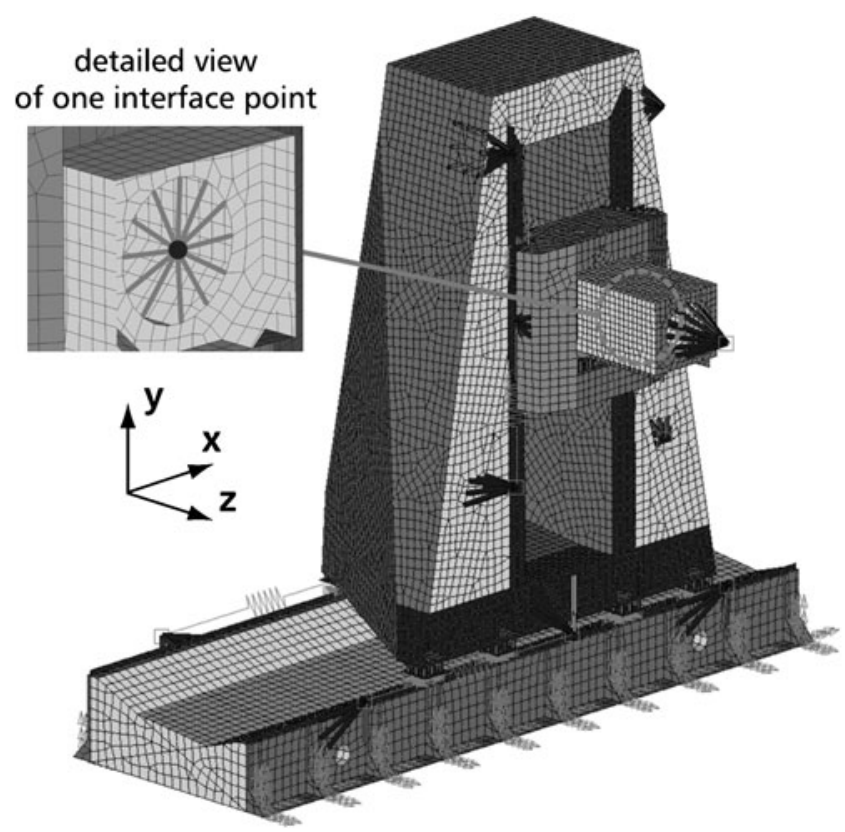

Fig. 8 FEM model of the machine frame

The linear, time-invariant state space model in modal coordinates is written as

$$
\begin{aligned}
\dot{\mathbf{q}}_{S} & =\mathbf{A} \cdot \mathbf{q}_{S}+\mathbf{B} \cdot \mathbf{u} \\
\mathbf{y} & =\mathbf{C} \cdot \mathbf{q}_{S}
\end{aligned}
$$

with $\mathbf{u}$ being the input variables vector, $\mathbf{y}$ the vector of output variables, and $\mathbf{q}_{\mathrm{s}}$ the state vector composed of the modal coordinates $\mathbf{q}_{S}=\left[\begin{array}{ll}\dot{\mathbf{q}} & \mathbf{q}\end{array}\right]^{T}$. The state space matrices are defined as

$\mathbf{A}=\left[\begin{array}{cc}\mathbf{0} & \mathbf{E} \\ -\boldsymbol{\Lambda} & -\mathbf{C}_{q}\end{array}\right], \mathbf{B}=\left[\begin{array}{c}0 \\ \mathbf{V}^{T}\end{array}\right], \mathbf{C}=\left[\begin{array}{ll}\mathbf{V} & \mathbf{0}\end{array}\right]$

where $\boldsymbol{\Lambda}$ is the spectral matrix of eigenfrequencies, $\boldsymbol{C}_{\boldsymbol{q}}$ the diagonal matrix of modal damping, and $\boldsymbol{V}$ the modal matrix of eigenvectors.

The input equation of the state-space coupled system is a result of joining the equations of separate bodies into one system

$$
\left[\begin{array}{c}
{ }^{1} \dot{\mathbf{q}}_{S} \\
{ }^{2} \dot{\mathbf{q}}_{S}
\end{array}\right]=\left[\begin{array}{cc}
{ }^{1} \mathbf{A} & 0 \\
0 & { }^{2} \mathbf{A}
\end{array}\right] \cdot\left[\begin{array}{c}
{ }^{1} \mathbf{q}_{S} \\
{ }^{2} \mathbf{q}_{S}
\end{array}\right]+\left[\begin{array}{cc}
{ }^{1} \mathbf{B} & 0 \\
0 & { }^{2} \mathbf{B}
\end{array}\right] \cdot\left[\begin{array}{c}
{ }^{1} \mathbf{u} \\
{ }^{2} \mathbf{u}
\end{array}\right]
$$

with the superscript 1 representing body 1 (machine frame) and superscript 2 representing body 2 (spindle).

Mutual force interaction between the bodies is defined as

$-{ }^{1} u_{i}={ }^{2} u_{i}=k_{i} \cdot\left({ }^{1} x_{i}-{ }^{2} x_{i}\right)$

With the vector of linear displacements $x=\boldsymbol{V} \cdot q$ expressed as a linear combination of shape matrix $\boldsymbol{V}$ and modal 
coordinates $q$, after substitution of Eq. 4 into Eq. 3, the input equation is obtained in the form of

$$
\left[\begin{array}{c}
{ }^{1} \dot{\mathbf{q}}_{S} \\
{ }^{2} \dot{\mathbf{q}}_{S}
\end{array}\right]=\left[\begin{array}{ll}
\mathbf{A}_{C 1} & \mathbf{A}_{C 2} \\
\mathbf{A}_{C 3} & \mathbf{A}_{C 4}
\end{array}\right] \cdot\left[\begin{array}{c}
{ }^{1} \mathbf{q}_{S} \\
{ }^{2} \mathbf{q}_{S}
\end{array}\right]+\left[\begin{array}{cc}
{ }^{1} \mathbf{B}_{r} & 0 \\
0 & { }^{2} \mathbf{B}_{r}
\end{array}\right] \cdot\left[\begin{array}{l}
{ }^{1} \mathbf{u}_{r} \\
{ }^{2} \mathbf{u}_{r}
\end{array}\right]
$$

in which matrix $\boldsymbol{A}$ is filled with new elements and matrix $\boldsymbol{B}$ and vector $u$ contain only displacements of nodes $r$ which are kept as external inputs of the coupled system. In the case of the spindle and machine frame model, the system is excited externally at the front of the spindle.

The output equation of the coupled system is written as

$\mathbf{y}_{C}=\mathbf{C} \cdot\left[\begin{array}{ll}{ }^{1} & \mathbf{q}_{S} \\ { }^{2} & \mathbf{q}_{S}\end{array}\right]$

with the vector of output coordinates $y_{C}$ and matrix $\boldsymbol{C}$ defined as

$\mathbf{C}=\left[\begin{array}{llll}{ }^{1} \mathbf{C}_{r} & \mathbf{0} & { }^{2} \mathbf{C}_{r} & \mathbf{0}\end{array}\right]$,

in which the ${ }^{1} \boldsymbol{C}_{\boldsymbol{r}}$ and ${ }^{2} \boldsymbol{C}_{\boldsymbol{r}}$ submatrices only contain the displacements of nodes $r$.

\section{Verification of the model}

\subsection{Spindle model verification}

There is a group of three bearings with TBT arrangement at the front end of the spindle (Fig. 9). The front group uses FAG HCB $71922 \mathrm{E}$ bearings. The spindle rear end only has one FAG HC $71914 \mathrm{E}$ bearing. The front and rear bearing groups have constant preload, defined in the model by means of springs. The model of the bearing mentioned in chapter 3.2 enables calculation of the bearing stiffness as a function of shaft revolution (Fig. 10). The influence of the thermal field inside the spindle on bearing stiffness can be neglected because of the dominating effect of the bearings' spring preload [38].

The spindle geometry was modeled using the method described in chapter 3.2. The spindle shaft FE mesh before reduction is shown in Fig. 11. The mass and stiffness of the shaft are described with a FE mesh using parabolic brick

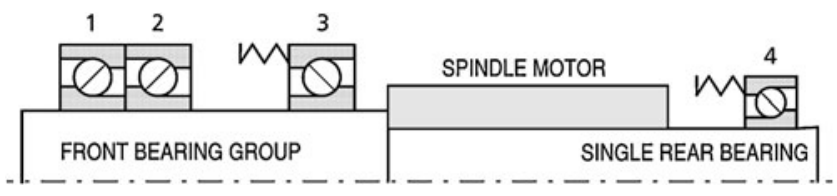

Fig. 9 Spindle bearings arrangement

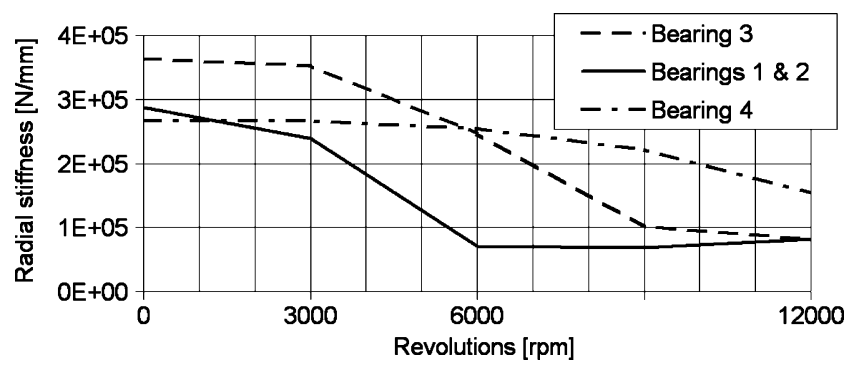

Fig. 10 Bearing stiffness as a function of revolutions

elements. The additional masses like motor rotor or draw bar are modeled with beam elements connecting the points of the FE mesh reduction.

The spindle model has been verified by comparing the computed and measured FRFs evaluated at the spindle nose. The spindle unit was suspended on curtains during the measurements (Fig. 3). In the computational model the influence of the curtain was simulated using additional spring elements connected to the spindle housing. The damping values for the model were obtained from measurement results.

A comparison of the calculated and measured FRF is shown in Fig. 12. The dominant compliance of the spindle occurs at the eigenfrequency of $856 \mathrm{~Hz}$, where very good agreement between the measured and simulated values of both the critical compliance and its corresponding frequency can be seen. There are other secondary eigenfrequencies with an elevated compliance in the range between 1,200 and $2,000 \mathrm{~Hz}$. A good correspondence between the computational model and the measurement results has been found in terms of compliance values. However, there are some discrepancies in the simulated eigenfrequency values. Looking at the eigenshapes (Fig. 13), we can see that the forms at the frequencies of 1,281 and $1,975 \mathrm{~Hz}$ are characterized by bending in middle section of the shaft. In this part of the shaft, the stator of the motor are placed. The stator model could only be created in a simplified form using the beam elements (Fig. 11) due to a lack of detailed information on the spindle design and the connection between the spindle rotor and the spindle shaft. Inaccuracy of the simulation model may be attributed to this simplification of the model.

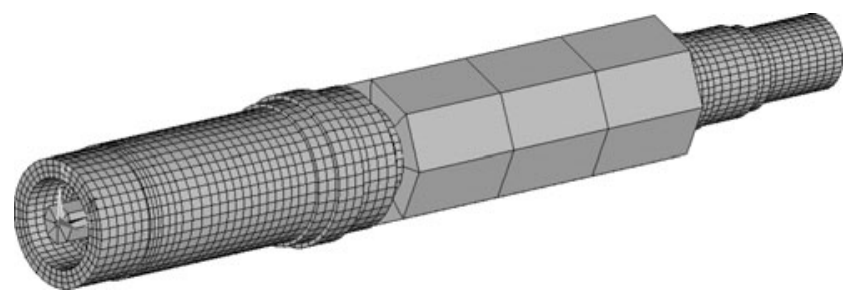

Fig. 11 FE mesh of spindle shaft before reduction 


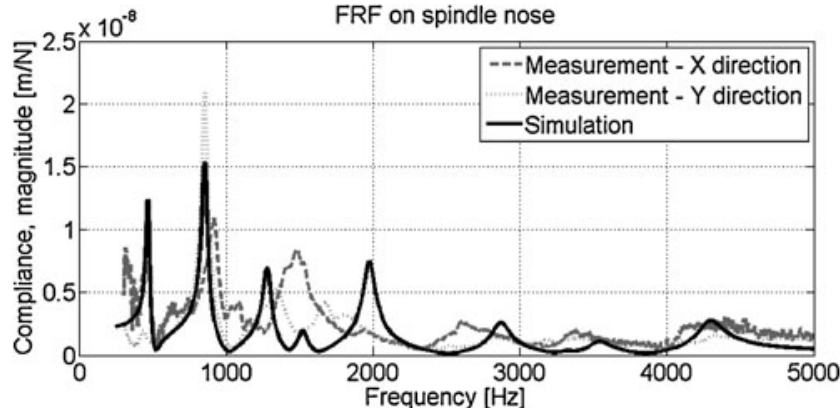

Fig. 12 Comparison of the measured and calculated FRF of the separate spindle

4.2 Verification of the coupled model using FRF measurement

The coupled model included 50 eigenfrequencies of the machine frame model and all of the eigenfrequencies of the reduced free spindle model.

In the case of a spindle without a tool, the dominant compliances of the system occur in the low frequency range of up to ca $120 \mathrm{~Hz}$. A comparison between the measurement and the coupled model can be seen in Fig. 14. A detail of the low frequency range is in Fig. 15. In the above-mentioned frequency range, there is good agreement between the values of the critical frequencies and their corresponding compliances determined using the coupled model on the one hand and the measurements on the other. It is obvious that these frequencies relate to the vibration of the machine frame. At the simulated frequency value of $54 \mathrm{~Hz}$, the whole column is
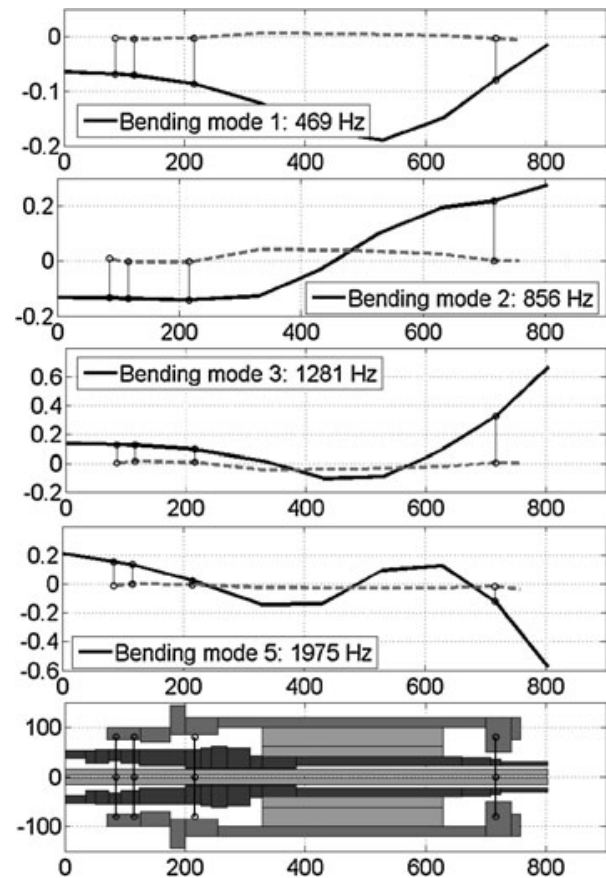

Fig. 13 Selected eigenshapes of the spindle model

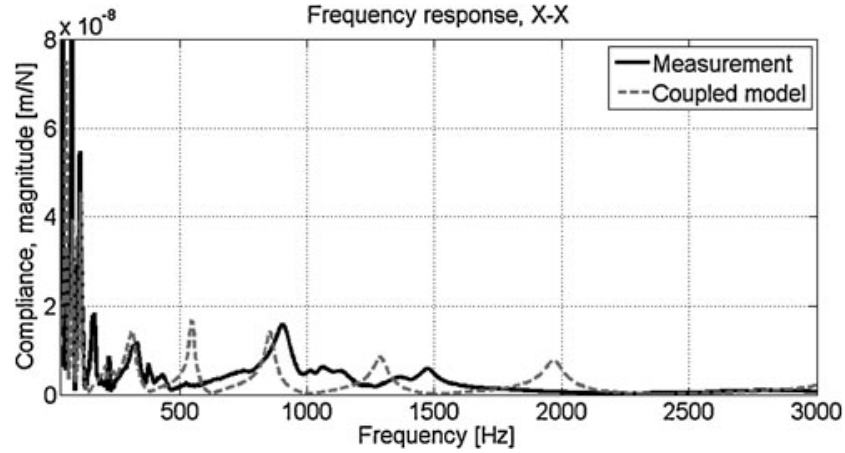

Fig. 14 FRF at the spindle nose without tool

deformed in the $\mathrm{XY}$ plane in a parallelogram-like shape; at the frequency of $81 \mathrm{~Hz}$, the free end of the ram oscillates; at the frequency of $109 \mathrm{~Hz}$, the ram bends and twists together with the column (Fig. 16). In the higher frequency range, the compliances at the critical frequencies close to 310 and 850 $900 \mathrm{~Hz}$ are well captured by the coupled model.

The behavior of the FRF with the H50 face milling cutter tool reveals similar characteristics as in the case without the tool; the critical compliances of the system occur in the low frequency range. Good agreement between the measurement and the simulation is also found close to the frequencies of 300 and $850 \mathrm{~Hz}$ (Fig. 17). The lack of agreement between the measurement and the simulation results for the frequency range of above $1,000 \mathrm{~Hz}$ may result from the simplified modeling of the spindle shaft, as explained in the previous chapter.

With the slim S32M shank cutter tool, the dominant compliance occurs above $1,000 \mathrm{~Hz}$. The tool is the most compliant part of the system in this case. Between the measured $(1,180 \mathrm{~Hz})$ and simulated $(1,060 \mathrm{~Hz})$ value there is a difference of about $11 \%$ (Fig. 18).

\subsection{Coupled model verification using cutting tests}

The above-mentioned findings were verified by a cutting test using $\mathrm{C} 45$ steel. The steel has a cutting resistance of

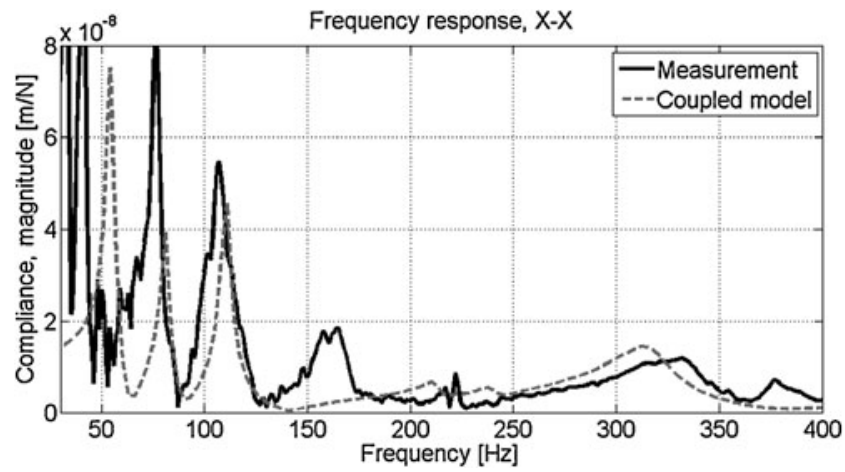

Fig. $15 \mathrm{FRF}$ at the spindle nose without tool. Detail of the low frequency range 


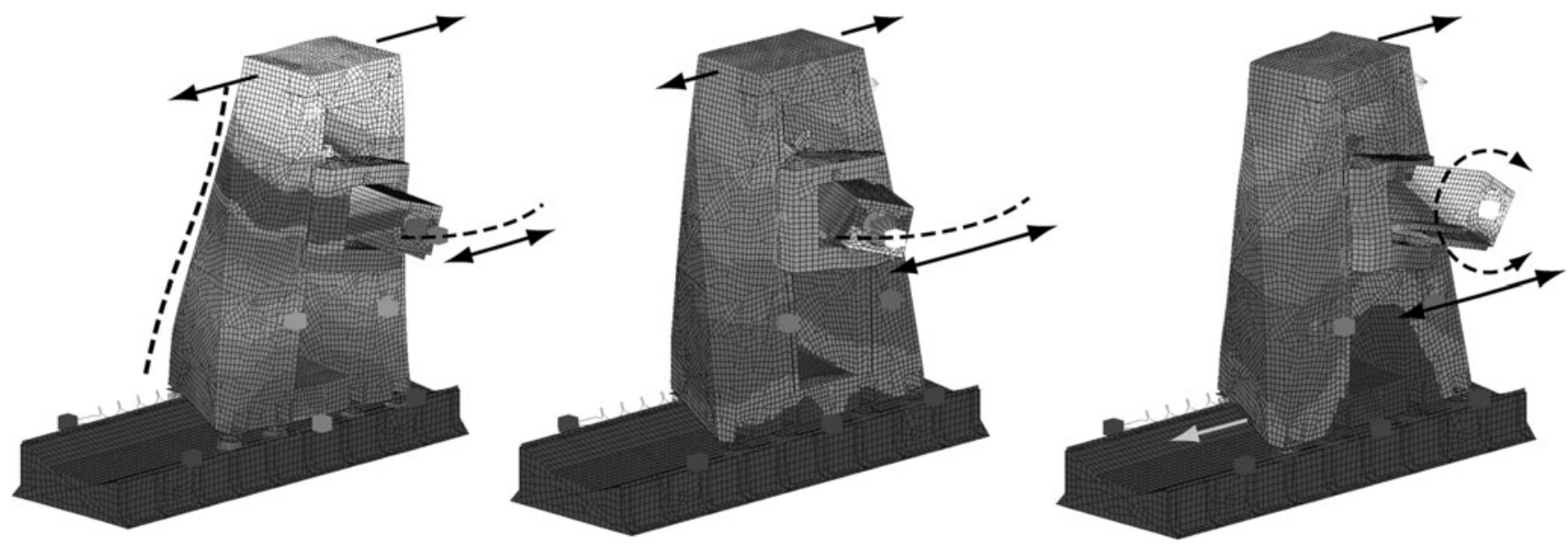

Fig. 16 Computed deformations of the machine frame at the frequencies of $54 \mathrm{~Hz}$ (top left), $81 \mathrm{~Hz}$ (right), and $109 \mathrm{~Hz}$ (bottom left)

$K_{\mathrm{c}}=2,000 \mathrm{MPa}$. The H50 face milling cutter was equipped with Walter ADMT160608R-F56 inserts, with WSP45 coating. The cutting parameters were: ae $=45 \mathrm{~mm}$, ap $=$ $12 \mathrm{~mm}, \mathrm{fz}=0.15 \mathrm{~mm}, n=1,300$ and $1,600 \mathrm{rpm}, \mathrm{vc}=204$, and $251 \mathrm{~m} / \mathrm{min}$. An accelerometer was installed at the ram end.

The frequency spectrum of the acceleration signal for two values of the spindle revolutions can be seen in Fig. 19. The cutting process was stable in both cases of the cutting conditions. The dominant amplitude at $107 \mathrm{~Hz}$ can be seen in the detail on the bottom left part of Fig. 19. It is the third eigenfrequency of the machine frame excited by a tooth passing frequency of $108 \mathrm{~Hz}$ (see Figs. 15 and 16). There is also another peak at $73 \mathrm{~Hz}$, which relates to the second eigenform of the machine frame. This eigenform was measured at a frequency value of $76 \mathrm{~Hz}$ on the machine in static state. This discrepancy could be attributed to the influence of the feed drives.

The dominant amplitude at $107 \mathrm{~Hz}$ can also be seen in the detail on the bottom right part of Fig. 19. The vibration magnitude is smaller because the system is excited by a tooth passing frequency of $133 \mathrm{~Hz}$.

There is also an important vibration magnitude at 533 and $541 \mathrm{~Hz}$. These frequencies are near the spindle first frequency (see Fig. 13). In case of 1,600 rpm, the system vibrations near the spindle first frequency are greater than the machine structure vibrations at 107 and $133 \mathrm{~Hz}$. This means that the spindle vibrates with the structure. If the tool revolution decreases to $1,300 \mathrm{rpm}$, the spindle vibrations at $541 \mathrm{~Hz}$ decrease and the frame vibrations at 73 and $107 \mathrm{~Hz}$ increase. We can see that during stable cutting, the dominant vibration magnitude shifts between the structure frequencies and the spindle frequencies depending on spindle revolutions.

The dominant compliance of the S32M shank cutter can be found in the spectrum of vibration signal, as measured by a cutting test using $\mathrm{C} 45$ steel. The tool was again equipped with Walter ADMT160608R-F56 inserts with WSP45 coating. The cutting parameters were: $a e=32 \mathrm{~mm}$, $\mathrm{ap}=3 \mathrm{~mm}, \mathrm{fz}=0.12 \mathrm{~mm}, n=2,100 \mathrm{rpm}$, and $\mathrm{vc}=211 \mathrm{~m} / \mathrm{min}$. The spectrum of acceleration signal is shown in Fig. 20.

The cutting conditions caused instability in the cutting process. The tool eigenfrequency at $1,173 \mathrm{~Hz}$ can be seen in the detail on the bottom part of Fig. 20. There are also other peaks resulting from the unstable cut. The peaks have a distance of $35 \mathrm{~Hz}$ which is the revolution frequency. In this case, the tool is the most compliant part of the system, which is also what the model indicates.

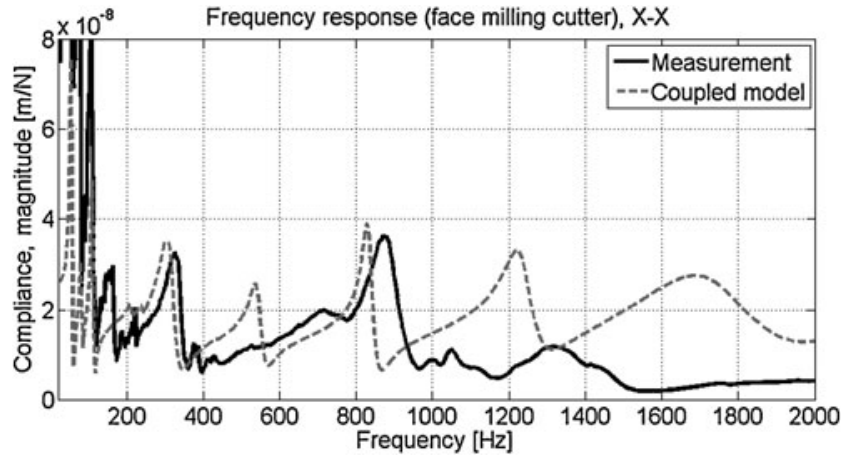

Fig. 17 FRF with the H50 face milling cutter

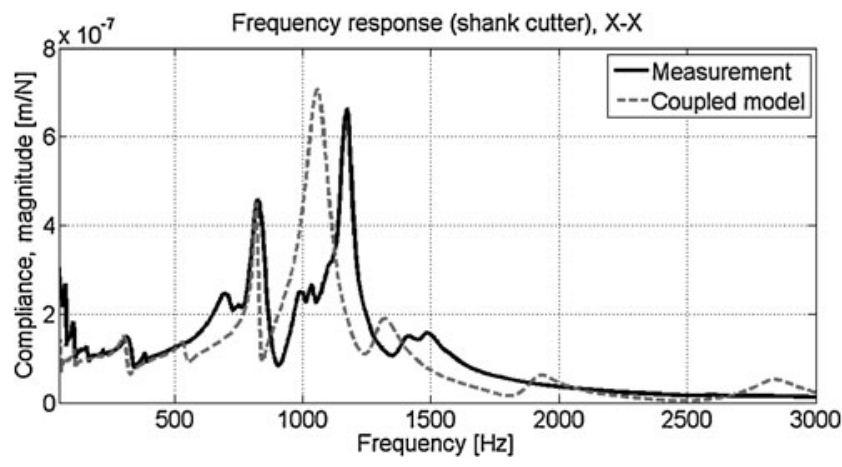

Fig. 18 FRF with the S32M shank cutter 

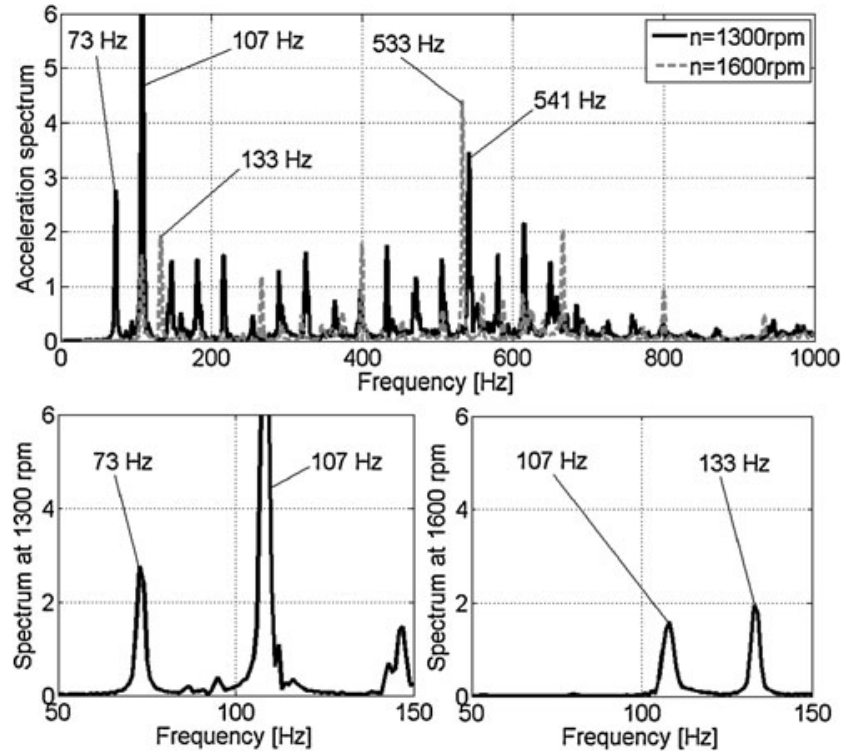

Fig. 19 Acceleration spectrum measured at the ram end. Face milling cutter with a diameter of $50 \mathrm{~mm}$, ae $=45 \mathrm{~mm}, a p=12 \mathrm{~mm}$, and $\mathrm{fz}=0.15 \mathrm{~mm}$

\section{Discussion}

The machine tool frame influences dynamic properties of the tool and spindle in two ways-by its stiffness and damping. The frame represents a structure with limited stiffness which supports the spindle system. Interaction of the machine frame and spindle causes a shift of the spindle eigenfrequencies. The machine frame structure contributes also to an increased level of structural damping evaluated at the tool end point or the spindle (see Figs. 6 and 7). The results of simulations and experiments prove that for

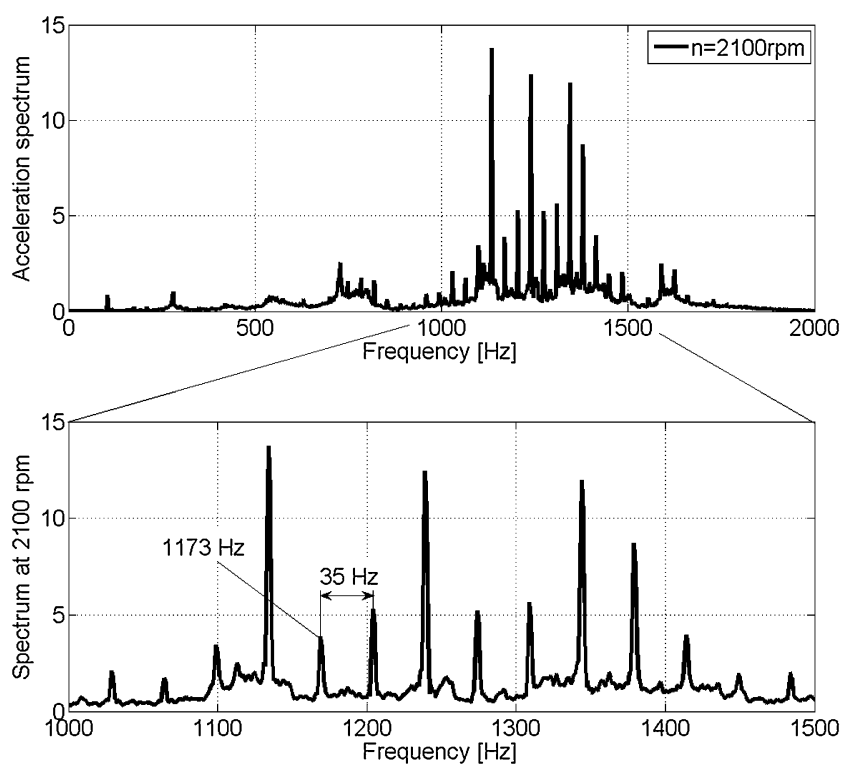

Fig. 20 Acceleration spectrum measured at the ram end. Shank cutter with a diameter of $32 \mathrm{~mm}$, ae $=32 \mathrm{~mm}$, ap $=3 \mathrm{~mm}$, and $\mathrm{fz}=0.12 \mathrm{~mm}$ relevant predictions of stable machining parameters, it is important to extend the spindle and tool model by the machine frame model.

In specific cases (e.g., if stiff and compact face milling cutter is used), the machine frame stiffness can show higher dynamical compliance than that of the spindle and tool system. Machine frame features low structural eigenfrequencies, typically up to $200 \mathrm{~Hz}$. Importance of the low frequency compliance can be shown especially in roughing machining, which can excite the machine tool frame. For such applications, the machine tool structure can become a limiting part of the whole dynamic system. In those cases, enhancement of the cutting parameters can be obtained primarily by optimizing the machine tool structure, employing the structural optimization or unconventional materials (discussed, e.g., in [31]).

Assumption of the machine frame impact on the dynamic system properties has been proved by cutting tests as well. It has been found that the vibration spectrum contains peaks related to the machine tool structure eigenforms and to the first spindle eigenform as well, if compact face milling cutter is used. Cutting tests showed also that a certain vibration magnitude clearly relates to the spindle revolutions, which define the system excitation frequency and its harmonics.

On the other hand, machining with slim tools is usually not affected by the properties of the machine tool frame since only one frequency resulting from the bending vibration of the tool is critical. In this case, the whole machine structure shows its influence only indirectly through changed levels of structural damping. This behavior was confirmed both by the tool end point hammer hit tests and machining tests using the slim shank cutter as well.

\section{Conclusions}

Properties of the spindle and tool system connected with the machine tool frame have been simulated using a coupled model. The model is based on coupling the modally reduced FE machine frame model and the spindle detailed model with the tool. Properties of the coupled model have been experimentally verified both by the hammer hit tests at the tool end point and by the cutting tests as well. Good match between the simulated and measured properties has been found.

The strategy of modeling the spindle, tool, and machine frame system as a multi-body system, in which the reduced FE models are coupled, represents an effective tool for investigation of the dynamic properties at the tool tip for a number of various combinations of machine tool structures, spindles, and tools. Future work will focus in more detail on research of the feed drive control influence on the 
dynamic properties of the whole system. For this purpose, the coupled model will be extended by the ball screw feed drive model including the control in all of the motion axes. Verification tests based on the machine tool structure excitation by the feed drives are planned.

Acknowledgment This research has been supported by the 1M0507 grant of the Ministry of Education of the Czech Republic.

\section{References}

1. Albertelli P, Leonesio M, Bianchi G (2007) Spindle-machine tool interaction and cutting process stability. AITeM Conference, Montecatini Terme, Italy

2. Altintas Y, Budak E (1995) Analytical prediction of stability lobes in milling. CIRP Ann 44(1):357-362

3. Altintas Y, Weck M (2004) Chatter stability of metal cutting and grinding. CIRP Ann 53(2):619-642

4. Arnold RN (1946) The mechanism of tool vibration in the cutting of steel. Proc Inst Mech Eng Lond 154:261-276

5. Budak E, Altintas Y (1998) Analytical prediction of chatter stability conditions for multi-degree of freedom systems in milling, Part I: modeling, Part II: applications. J Dyn Syst Meas Control 120:22-36

6. Cao Y, Altintas Y (2007) Modeling of spindle-bearing and machine tool systems for virtual simulation of milling operations. Int J Mach Tools Manuf 47(9):1342-1350

7. Hanna NH, Tobias SA (1974) A theory of nonlinear regenerative chatter. J Eng Ind 96:247-255

8. Harris TA (1991) Rolling bearings analysis, 3rd edn. Wiley, New York

9. Hoffman F, Brecher C (2005) Simulation von Verfahroperationen. Werkstattstechnik Online 95(7/8):506-512

10. Holkup T, Cao H, Kolar P, Altintas Y, Zeleny J (2010) Thermomechanical model of spindles. CIRP Ann 59(1):365-368

11. Jones AB (1960) A general theory for elastically constrained ball and radial roller bearings under arbitrary load and speed conditions. J Trans ASME Basic Eng 82:309-320

12. Kashirin AJ (1944) Research of vibrations in metal cutting. Izdatelstvo AN SSSR, Moscow, In Russian

13. Koenigsberger F, Tlusty J (1967) Machine tool structures: stability against chatter, vol. I., Pergamon

14. Kolar P, Holkup T (2007) Modeling of a machine tools spindle using a hybrid model. Proc. of 3 rd Int. Conf.-Virtual Design and Automation. Paper No. S05_06_01_kolar

15. Kreis M (2008) Zum Eigenverhalten von Motorspindeln unter Betriebsbedingungen: Einflüsse und Konsequenzen für die Prozessstabilität. Ph.D. thesis, TU Darmstadt

16. Lehner M, Eberhard P (2006) Modelreduktion in elastischen Mehrkörpersystemen. Automatisierungstechnik 54(4):170-177

17. Li H, Shin YC (2003) Analysis of bearing configuration effects on high speed spindles using an integrated dynamic thermomechanical spindle model. Int J Mach Tools Manuf 44:347-364

18. Li H, Shin YC (2004) Integrated dynamic thermo-mechanical modeling of high speed spindles, part 1: model development, part 2: solution procedure and validation. Trans ASME, J Manuf Sci Eng 126(148-158):159-168

19. Lin CW, Tu JF, Kamman J (2003) An integrated thermomechanical-dynamical model to characterize motorized machine tool spindles during very high speed rotation. Int J Mach Tools Manuf 43:1035-1050
20. Maj R, Bianchi G (2005) Mechatronic analysis of machine tools. 9th SAMTECH Users Conference

21. Merrit H (1965) Theory of self-excited machine tool chatter. J Eng Ind 87(4):447-454

22. Nelson HD, McVaugh JM (1976) The dynamics of rotor-bearing systems using finite elements. J Eng Ind 93(2):593-600

23. Nelson HD (1980) A finite rotating shaft element using Timoshenko beam theory. J Mech Des 102:793-803

24. Park SS, Altintas Y, Movahhedy M (2003) Receptance coupling for end mills. Int J Mach Tools Manuf 43:889-896

25. Rantatalo M, Aidanpää JA, Göransson B, Normand P (2007) Milling machine spindle analysis using FEM and non-contact spindle excitation and response measurement. Int $\mathrm{J}$ Mach Tools Manuf 47(7-8):1034-1045

26. Schmitz TL (2000) Predicting high-speed machining dynamics by substructure analysis. CIRP Ann 49(1):303-308

27. Schmitz TL, Davies MA, Kennedy MD (2001) Tool point frequency response prediction for high-speed machining by RCSA. Trans ASME, J Manuf Sci Eng 123(4):700-707

28. Schmitz TL, Duncan GS (2005) Three-component receptance coupling substructure analysis for tool point dynamics prediction. Trans ASME, J Manuf Sci Eng 127(4):781-790

29. Siedl D (2007) Flexible Mehrkörpersimulation im Entwicklungsprozess von Werkzeugmaschinen. Seminarberichte iwb (2007) 88: Mechatronik-Vorsprung durch Simulation. Garching, München, 2007, pp 4-2-4-21

30. Smith KS, Winfough WR, Halley J (1998) The effect of tool length on stable metal removal rate in high speed milling. CIRP Ann 47(1):307-310

31. Smolik J (2008) Primary structural parts of machine tools made from unconventional materials. International Congress MATAR PRAHA 2008 - Proceedings of Part 1: Drives \& Control, Design, Models \& Simulation, pp 65-70. ISBN 978-80-903421-9-4

32. Soucek $P$ (2008) Feed drive influence on machining process stability. Int. Congress MATAR PRAHA-Proc. of Part 2: Testing, Technology, pp 75-80. ISBN 978-80-904077-0-1

33. Shi HM, Tobias SA (1984) Theory of finite amplitude machine tool instability. Int J Mach Tool Des Res 24(1):45-69

34. Shridar R, Hohn RE, Long GW (1968) A stability algorithm for the general milling process. J Eng Ind 90:330

35. Taylor FW (1907) On the art of cutting metals. Trans ASME 28:31-350

36. Tlusty J, Polacek H (1957) Beispiele der behandlung der selbsterregten schwingung der werkzeugmaschinen. Fo Ko Ma, Hanser Verlag, Munich

37. Tlusty J, Polacek H (1963) The stability of the machine tool against self-excited vibration in machining. ASME Prod Eng Res Conf, Pittsburgh

38. Tlusty J, Ismail F (1981) Basic non-linearity in machining chatter. CIRP Ann 30:229-304

39. Tlusty J, Ismail F (1983) Special aspects of chatter in milling. ASME J Vibration Stress Reliab Des 105:24-32

40. Tobias SA, Fishwick W (1958) The chatter of lathe tools under orthogonal cutting conditions. Trans ASME 80:1079

41. Tobias SA, Fishwick W (1958) Theory of regenerative machine tool chatter. The Engineer 205

42. Tobias SA (1965) Machine-tool vibration. Blackie and Sons Ltd, Glasgow

43. Vesely J, Sulitka M (2009) Machine tool virtual model. MM Sci J 2009:146-151

44. Zaeh M, Siedl D (2007) A new method for simulation of machining performance by integrating finite element and multibody simulation for machine tools. CIRP Ann 56(1):383-386 